\title{
Impact of Hyoscine Bromide Use on Polyp Detection Rate During Colonoscopy: A Systematic Review and Meta-Analysis
}

\author{
Muhammad Yasir Khan ${ }^{\mathrm{a}, \mathrm{e}}$, Ahmed Dirweesh ${ }^{\mathrm{b}}$, Waqas Javed Siddiqui ${ }^{\mathrm{c}, \mathrm{d}}$
}

\begin{abstract}
Background: Colorectal cancer (CRC) is a leading cause of death worldwide. Polyp detection rate (PDR) and adenoma detection rate (ADR) are key focus in endoscopic research for CRC screening and prevention. Use of anti-spasmodic agents during colonoscopy to help identify adenomas and polyps has remained a controversial topic. Hyoscine butyl bromide (HBB) is the most commonly used anti-spasmodic agent in patients undergoing colonoscopy. Some randomized controlled trials (RCTs) have questioned the clinical efficacy and safety of routine use of HBB for polyp and adenoma detection rates.
\end{abstract}

Methods: We conducted a systematic search in PubMed and MEDLINE from inception until February 10, 2018, for studies which compared HBB with placebo. We used RevMan version 5.3 for analysis. Procedural end-points were polyps, adenomas, and advanced adenoma detection rates, mean number of polyps detected and cecal intubation time.

Results: We included seven RCTs with 2,588 patients in our analysis. A total of 1,301 patients were randomized to HBB arm and 1,287 to the placebo arm. There was no significant difference in the primary outcome of polyp detection rate, 654 in HBB group vs. 616 in the placebo group, $($ odds ratio $(\mathrm{OR})=1.11$, confidence interval $(\mathrm{CI})=$ $0.93-1.34, \mathrm{P}=0.25)$. There was no difference in secondary outcomes of adenoma detection rate, 430 in HBB group vs. 396 in the placebo group, $(\mathrm{OR}=1.06, \mathrm{CI}=0.89-1.26, \mathrm{P}=0.51)$, advanced adenoma detection rate, 92 in $\mathrm{HBB}$ vs. 95 in placebo group $(\mathrm{OR}=0.95, \mathrm{CI}=0.70$ - 1.30, $\mathrm{P}=0.76)$, mean number of polyps detected (point estimate $=$ $0.12, \mathrm{CI}=0.00-0.23, \mathrm{P}=0.05)$, adenomatous polyps $(\mathrm{OR}=0.84, \mathrm{CI}$ $=0.39-1.81, \mathrm{P}=0.65)$ and cecal intubation time (point estimate $=$

Manuscript submitted June 8, 2018, accepted July 2, 2018

aDepartment of Medicine, Capital Health Regional Medical Center, Trenton, NJ, USA

${ }^{b}$ Department of Medicine, Division of Gastroenterology, University of Minnesota Medical Center, Minneapolis, MN, USA

'Department of Medicine, Drexel University College of Medicine, Philadelphia, PA, USA

dDepartment of Medicine, Hahnemann University Hospital, Philadelphia, PA, USA

${ }^{\mathrm{e}}$ Corresponding Author: Muhammad Yasir Khan, 750 Brunswick Ave, Trenton, NJ 08638, USA. Email: yasirdowite@gmail.com

doi: https://doi.org/10.14740/gr1057w
$0.73, \mathrm{CI}=-1.98-0.52, \mathrm{P}=0.25)$ between the two groups.

Conclusions: The use of HBB in patients undergoing colonoscopy does not appear to improve polyp or adenoma detection rates. It showed a non-significant trend of increased mean number of polyps detected with HBB.

Keywords: Colonoscopy; Hyoscine butyl bromide; Colorectal polyps; Colorectal adenomas; Advanced adenomas; Adenoma detection rate; Polyp detection rate

\section{Introduction}

Colorectal cancer (CRC) is one of leading cause of death due to cancers worldwide. Colonoscopy is the gold standard procedure for the diagnosis and treatment of several colonic disorders including benign and malignant neoplasms. Adenoma detection rate (ADR) is a key quality component and a well-recognized strategy in CRC secondary prevention. The incidence of CRC is declining due to early screening and removal of adenomas [1].

Polyp detection rate (PDR) and ADR have been the focus of endoscopic research and are widely used to measure the quality of colonoscopy [2]. Studies have shown that polyps or adenomas may remain undetected or missed [3]. Antispasmodic agents have a long history of use in colonoscopy for a variety of indications. The pathophysiology behind administering these agents is that it can increase the visualization of the colonic surface by reducing spasms and flattening haustral folds [4].

HBB is the most commonly used anti-spasmodic agent in patients undergoing colonoscopy. Multiple RCTs have been conducted using HBB and have shown variable results regarding PDR and ADR. In our meta-analysis, we have analyzed the results of all the RCTs available to date using HBB and their impact on PDR to provide a better understanding of the topic.

\section{Methods}

\section{Search strategy}

The systematic review and meta-analysis are conducted in accordance with the Preferred Reporting Items for Systematic 


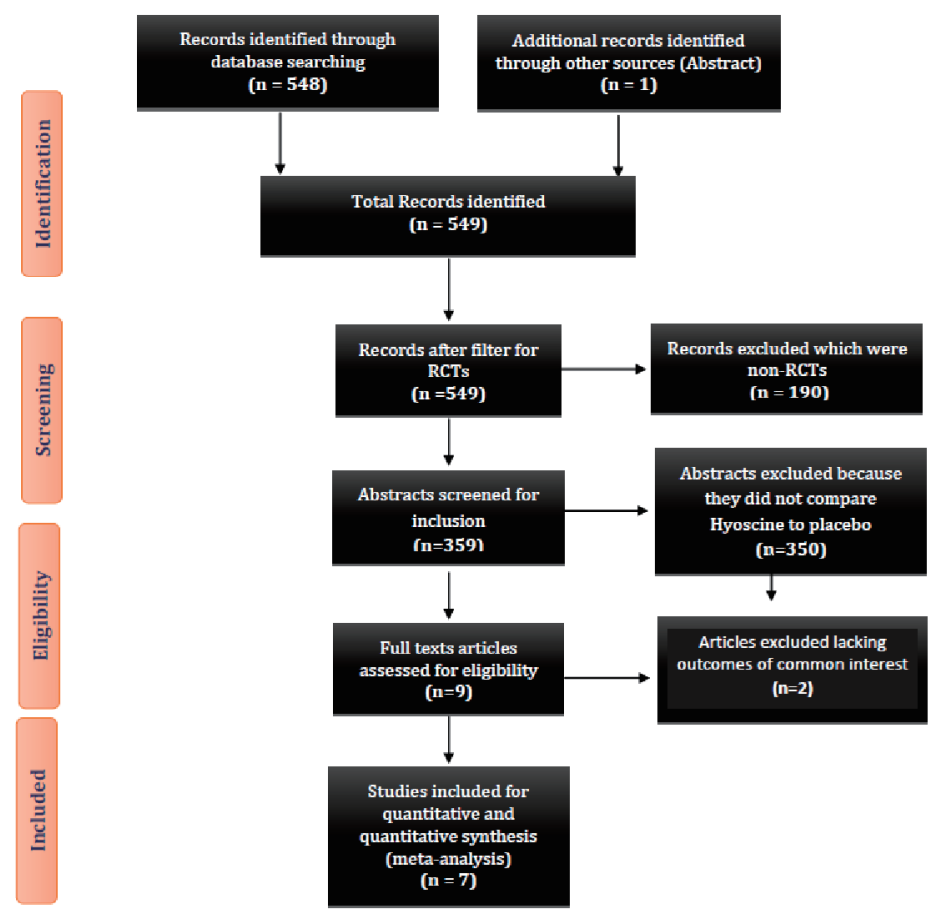

Figure 1. Showing the PRISMA 2009 study flow diagram. PRISMA: preferred reporting items for systematic reviews and metaanalyses; RCT: randomized control trial.

Reviews and Meta-analyses (PRISMA) guidelines [5].

\section{Data sources}

A planned literature search of MEDLINE and PubMed databases was conducted from inception to February 10, 2018 using Medical Subject Headings (MeSH) and keyword terms. Search terms used were combined with the Boolean operator "AND" and "OR." We used following search strategy for selecting studies (hyoscine butylbromide) OR (buscopan) OR (scopolamine) AND (adenoma) OR (polyp) AND (colonoscopy).

\section{Study selection protocol}

We selected RCTs in which patients were allocated to receive $\mathrm{HBB}$ or placebo at the time of cecal intubation. We used studies fulfilling the following inclusion criteria for analysis: 1) Prospective study design; 2) Adult patients $>18$ years of age; 3) Written in English; 4) PDR or ADR as an outcome for the study. Those studies which failed to meet these inclusion criteria were excluded.

A total of 548 articles were initially identified, using the $\mathrm{MeSH}$ term and keywords. We found one abstract from the literature search. We excluded 190 articles with the filter for RCTs. Totally, 359 trials were identified and reviewed in detail.
There were 350 studies which were excluded as they either did not compare hyoscine to placebo or were not randomized. Two studies lack endpoint of interests. Seven prospective RCTs were included for final comparison and statistical analysis (PRISMA diagram) (Fig. 1). Baseline characteristics and salient features of each study are summarized in Tables 1 and 2 [6-12].

\section{Outcomes for analysis}

The primary outcome measure was the PDR, defined as the proportion of patients in whom at least one polyp was detected. Secondary outcomes included: 1) The ADR, defined as the proportion of patients in whom at least one adenoma was detected; 2) The advanced ADR (AADR), defined as the proportion of patients in whom at least one advanced adenoma (i.e., adenoma $1 \mathrm{~cm}$ and/or adenoma with advanced histologic features, such as a villous component and/or high-grade dysplasia) was detected; 3) Mean number of polyps detected; 4) Cecal intubation time; 5) Polyp located proximal to the splenic flexure; 6) Polyp located distal to the splenic flexure; 7) Adenomatous polyps.

\section{Risk of bias and assessment of study quality}

Two authors (M.Y.K., and A.D) independently examined the titles and abstracts of all the articles to exclude irrelevant stud- 


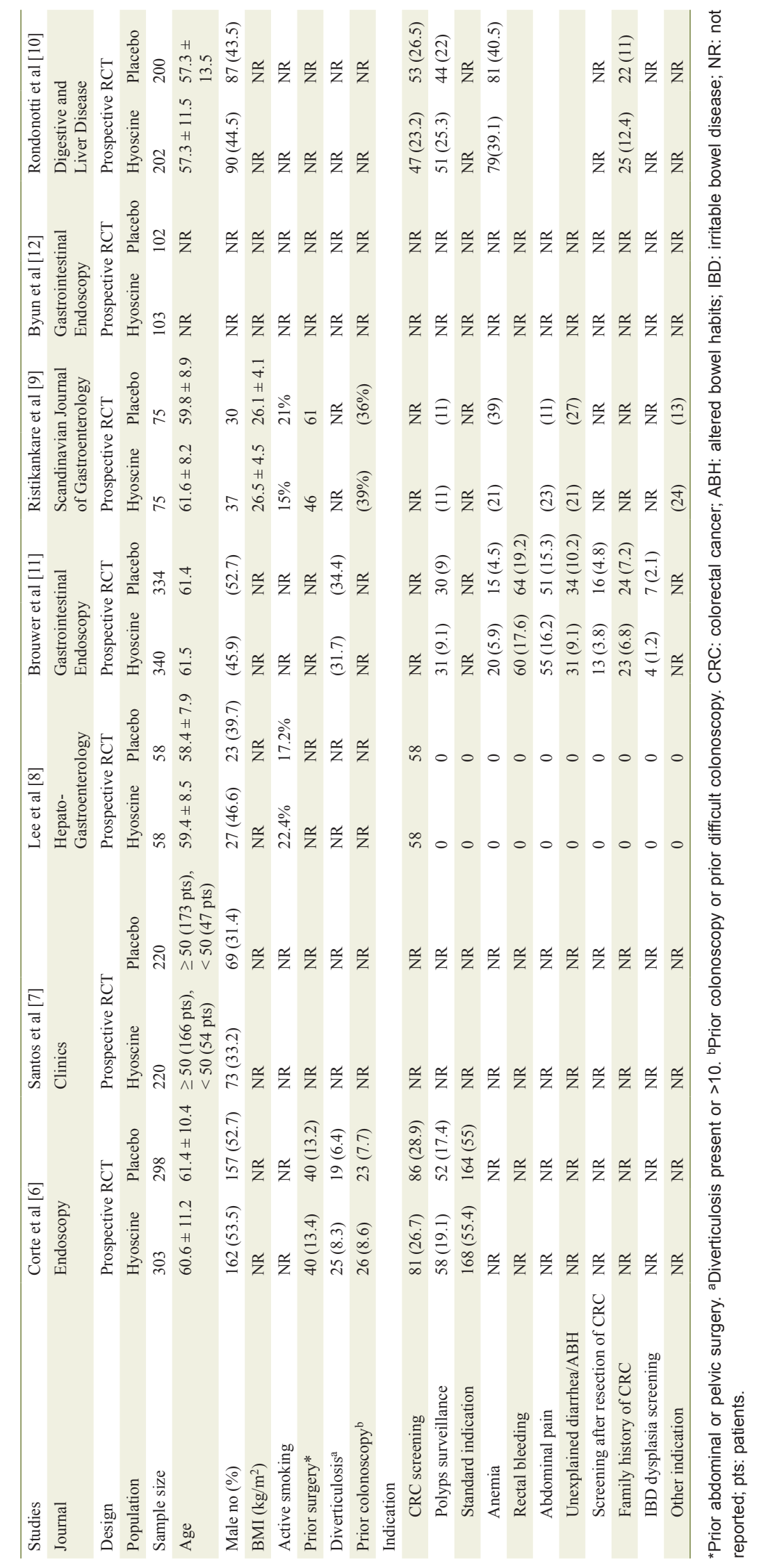



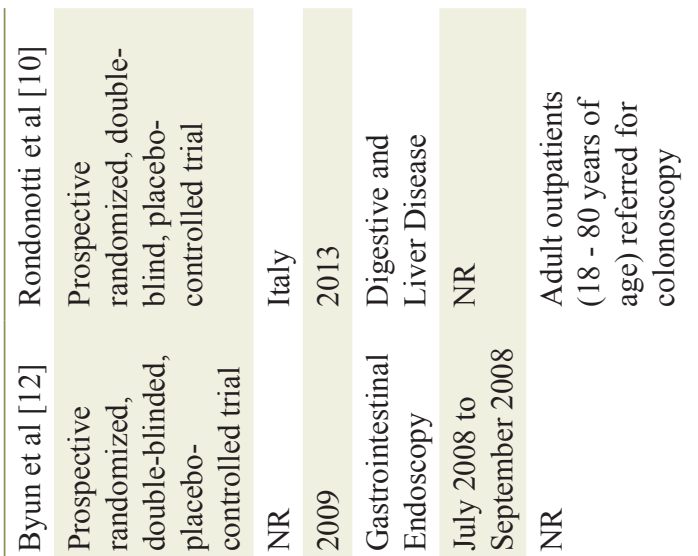

\section{$\tilde{z}$}
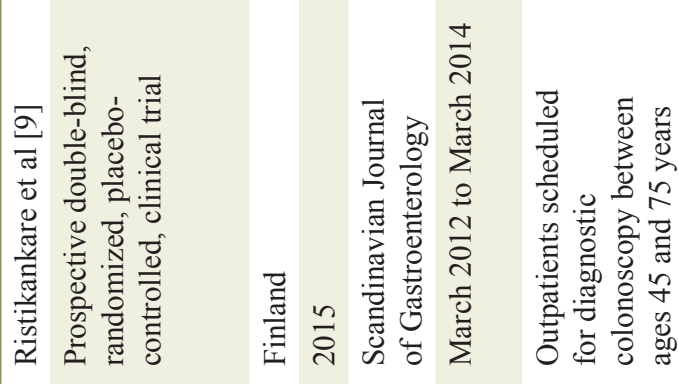

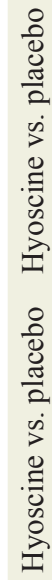
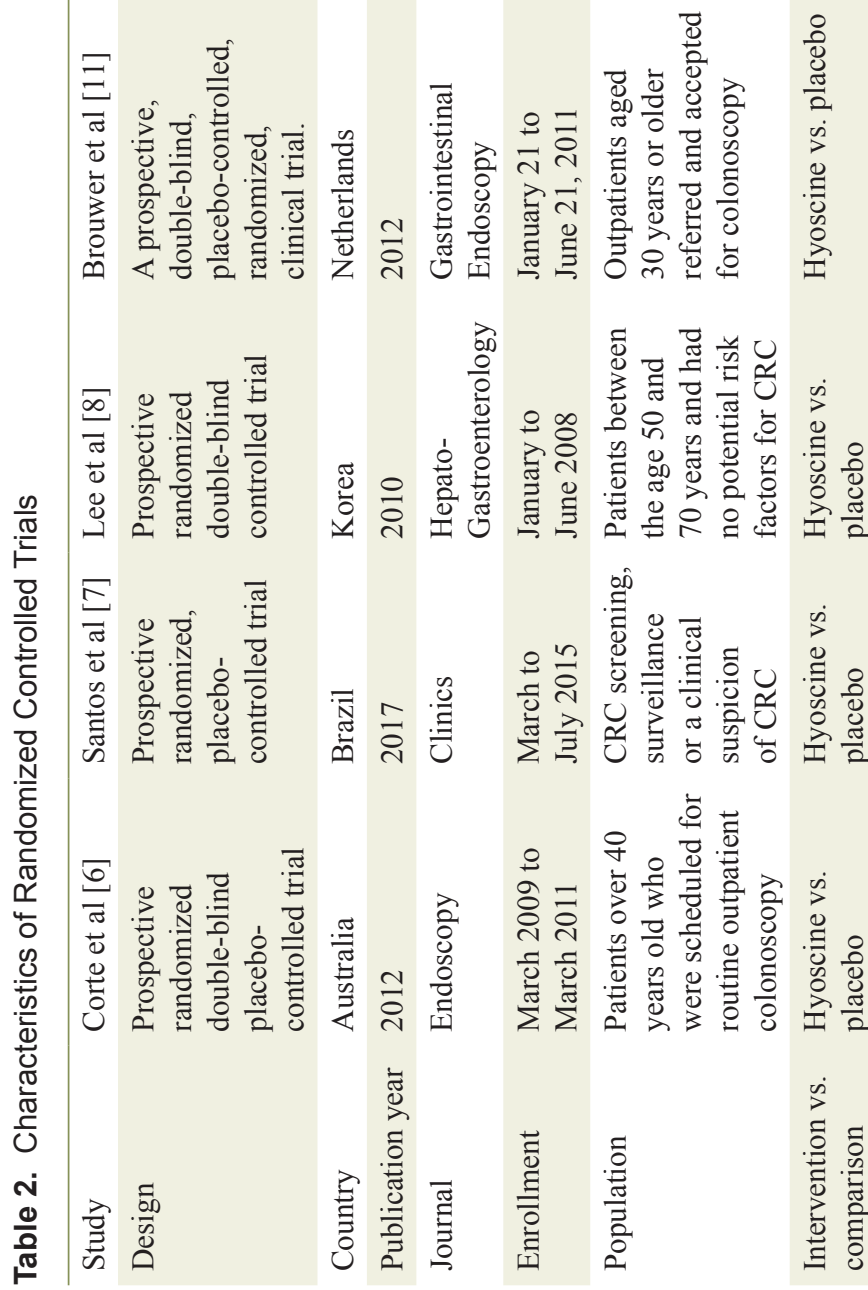

ies. Selected articles's full texts were individually assessed for eligibility based on the above-mentioned inclusion criteria. The Cochrane Collaboration's Risk of Bias tool was used to determine bias in the randomized trials meeting eligibility criteria [13].

\section{Data synthesis and analysis}

\section{Statistical method}

We performed statistical analysis using statistical software RevMan Version 5.3 Copenhagen. We used random effects model and Mantel-Haenszel method for the statistical analysis of dichotomous data to calculate the odds ratio, and we used inverse variance for the continuous data to estimate the mean difference. We also expressed our results using the forest plots. We considered two-sided $\mathrm{P}$-value of $<0.05$ as statistically significant.

We used seven RCTs for our analysis. We summarized baseline characteristics in Table 1 and characteristics of individual RCT in Table 2. We utilized Cochrane collaboration's tool risk assessment of bias in randomized trials for the quality assessment of RCTs, Table 3 [6-12].

\section{Heterogeneity}

We used $\mathrm{I}^{2}$ and $\mathrm{Chi}^{2}$ statistics to calculate the heterogeneity. Inter-study variability (variability between studies) compared to intra-study variability (variability within studies) was estimated with the $\mathrm{I}^{2}$ statistic. $\mathrm{I}^{2}>50 \%$ explains substantial heterogeneity as described in the Cochrane Handbook for Systematic Reviews for Interventions, Version 5.1.0, Part 2: General Methods for Cochrane Reviews [14]. We performed sensitivity analysis for substantial heterogeneity.

\section{Results}

\section{Qualitative analysis}

We included seven RCTs with 2,588 patients in our analysis. A total of 1,301 patients were randomized to hyoscine arm and 1,287 to the placebo arm.

The primary endpoint was polyp detection rate. The secondary endpoints were: 1) Adenoma detection rate; 2) Advanced lesion detection rate; 3) Mean number of polyps detected; 4) Cecal intubation time; 5) Polyp location proximal to the splenic flexure; 6) Polyp location distal to the splenic flexure; and 7) Adenomatous polyps.

\section{Primary endpoint}

\section{Polyp detection rate}

PDR was also similar between the two arms, with 654 in HBB group compared to 616 in the placebo group (odds ratio (OR) 
Table 3. Cochrane Risk of Bias

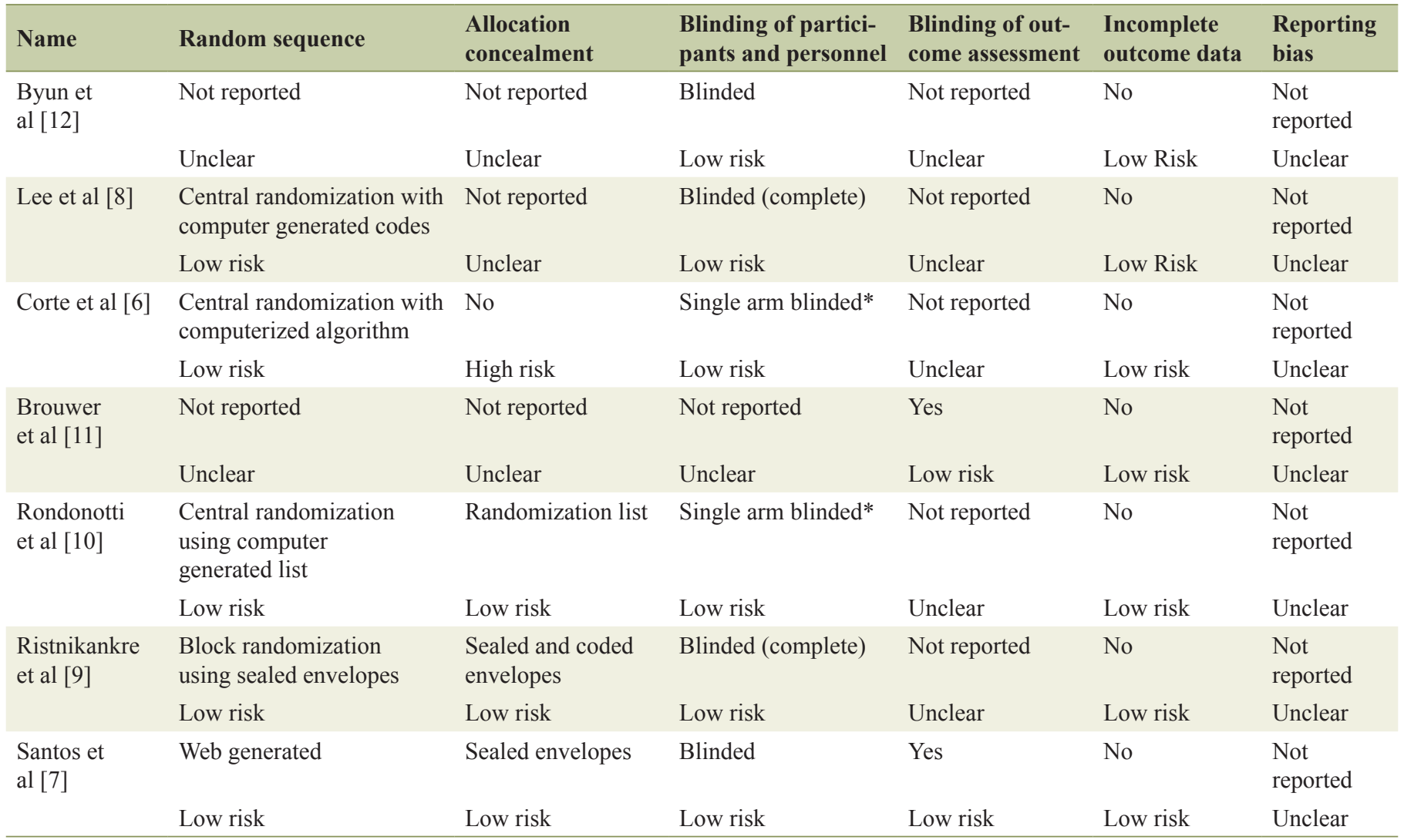

*Administering nurse not blinded.

$=1.11$, confidence interval $(\mathrm{CI})=0.93-1.34, \mathrm{P}=0.25, \mathrm{I}^{2}=$ 20\%) (Fig. 2).

\section{Secondary endpoints}

\section{Adenoma detection rate}

There was no difference in the ADR between the two groups,
430 in the HBB group vs. 396 in the placebo group $(\mathrm{OR}=1.06$, $\mathrm{CI}=0.89-1.26, \mathrm{P}=0.51, \mathrm{I}^{2}=0 \%$ ) (Fig. 3a).

\section{Advanced lesion detection rate}

There was no difference in the detection rate of advanced lesions, between the two arms, HBB arm had 92 vs. placebo arm had $95\left(\mathrm{OR}=0.95, \mathrm{CI}=0.70-1.30, \mathrm{P}=0.76, \mathrm{I}^{2}=0 \%\right)($ Fig. $3 b)$.

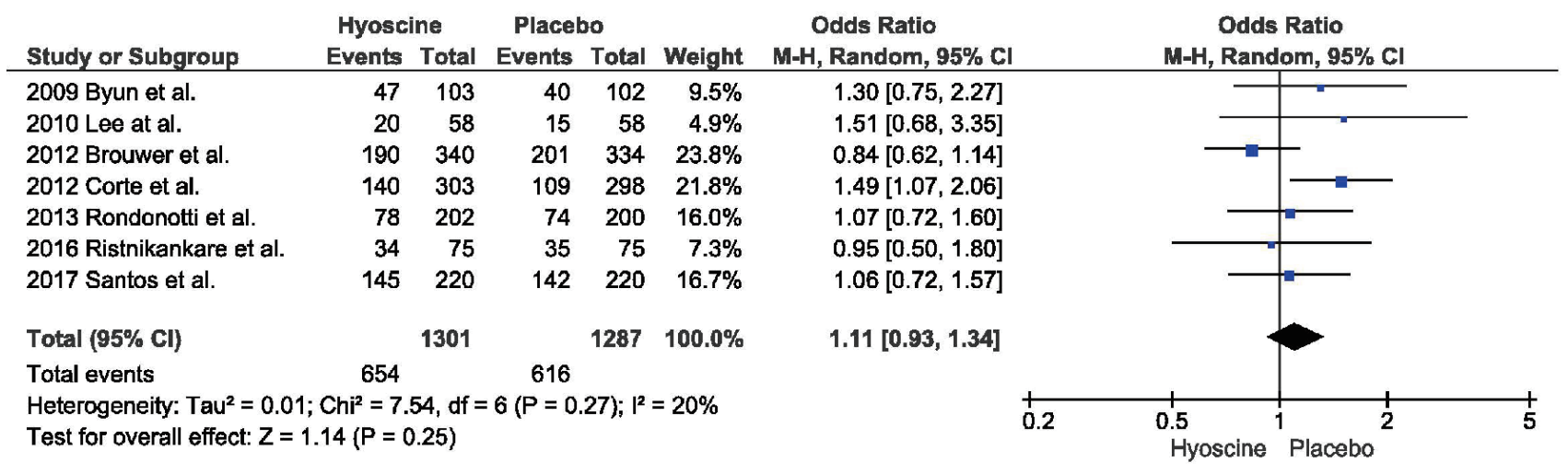

Figure 2. Primary outcome: polyp detection rate. 
a

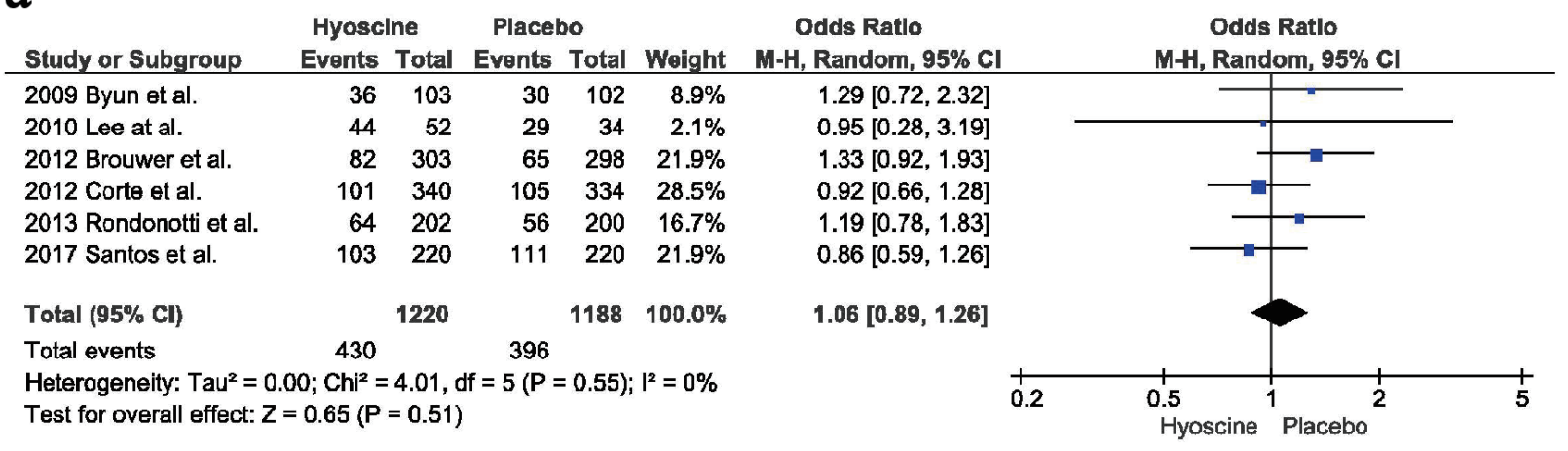

b

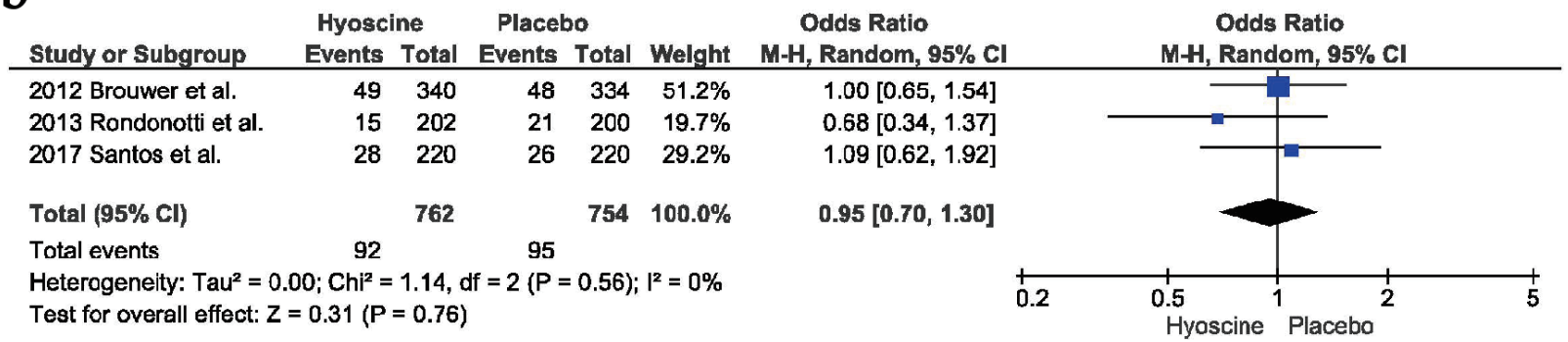

C

\begin{tabular}{|c|c|c|c|c|c|c|c|c|c|c|c|c|}
\hline \multirow[b]{2}{*}{ Study or Subgroup } & \multicolumn{3}{|c|}{ Hyoscine } & \multicolumn{3}{|c|}{ Placebo } & \multicolumn{2}{|r|}{ Std. Mean Difference } & \multirow{2}{*}{\multicolumn{4}{|c|}{$\begin{array}{l}\text { Std. Mean Difference } \\
\text { [V, Random, } 95 \% \mathrm{CI}\end{array}$}} \\
\hline & Mean & SD & Total & Mean & SD & Total & Weight & IV, Random, $95 \% \mathrm{Cl}$ & & & & \\
\hline 2010 Lee at al. & 0.9 & 1.8 & 58 & 0.6 & 1.2 & 58 & $10.3 \%$ & $0.19[-0.17,0.56]$ & & & & \\
\hline 2012 Corte et al. & 0.91 & 1.46 & 303 & 0.7 & 1.29 & 298 & $53.7 \%$ & $0.15[-0.01,0.31]$ & & & & \\
\hline 2013 Rondonotti et al. & 0.69 & 0.43 & 202 & 0.67 & 0.52 & 200 & $36.0 \%$ & $0.04[-0.15,0.24]$ & & & & \\
\hline Total $(95 \% \mathrm{Cl})$ & & & 563 & & & 556 & $100.0 \%$ & $0.12[-0.00,0.23]$ & & & & \\
\hline $\begin{array}{l}\text { Heterogeneity: } \operatorname{Tau}^{2}=0 \\
\text { Test for overall effect: } Z\end{array}$ & $\begin{array}{l}00 ; \mathrm{Chi}^{2} \\
=1.95(\mathrm{~F}\end{array}$ & $\begin{array}{l}=0.93 \\
=0.0\end{array}$ & $d f=2$ & $(P=0$ & $63) ; 1^{2}$ & $=0 \%$ & & & -0.5 & $\begin{array}{l}-0.25 \\
\text { Hyoscine }\end{array}$ & $\begin{array}{l}0 \\
\text { Placebo }\end{array}$ & 0.5 \\
\hline
\end{tabular}

Figure 3. Secondary outcomes: (a) Adenoma detection rate. (b) Advance adenoma detection rate. (c) Mean number of polyps detected.

\section{Mean number of polyps detected}

There was no difference in the mean number of polyps detected between the two arms, 563 in the HBB group vs. 556 in the placebo group with a point estimate of $0.12, \mathrm{CI}=-0.00-0.23$, $\mathrm{P}=0.05, \mathrm{I}^{2}=0 \%$ ) (Fig. 3c).

\section{Cecal intubation time}

Two studies reported the cecal intubation time. There was no difference between the two groups, with point estimate of $-0.73, \mathrm{CI}=-1.98-0.52, \mathrm{P}=0.25, \mathrm{I}^{2}=97 \%$. On running the sensitivity analysis without Ristikankare et al heterogeneity reduced to $0 \%$ with a trend towards decreased incubation time in the HBB arm compared to the placebo arm (Fig. 4a).

\section{Polyp location proximal to the splenic flexure}

There was no difference in the identification of polyps located proximal to splenic flexure, 198 in the HBB arm vs. 209 in the placebo arm, $\mathrm{OR}=0.89, \mathrm{CI}=0.59-1.35, \mathrm{P}=0.58, \mathrm{I}^{2}=52 \%$. Only two studies reported the location of polyps proximal to the splenic flexure; therefore we could not perform the sensitivity analysis (Fig. 4b).

\section{Polyp location distal to the splenic flexure}

Similarly there was no difference in the identification of polyps located distal to the splenic flexure, 224 in the HBB arm vs. 206 in the placebo arm, $\mathrm{OR}=1.19, \mathrm{CI}=0.86-1.63, \mathrm{P}=$ $0.29, \mathrm{I}^{2}=24 \%$ (Fig. $4 \mathrm{c}$ ).

\section{Adenomatous polyps}

There was no difference in the number of adenomatous polyps identified between the two groups, 295 in the HBB group vs. 298 in the placebo group, $\mathrm{OR}=0.84, \mathrm{CI}=0.39-1.81, \mathrm{P}=$ $0.65, \mathrm{I}^{2}=78 \%$. Only two studies reported this outcome; there- 


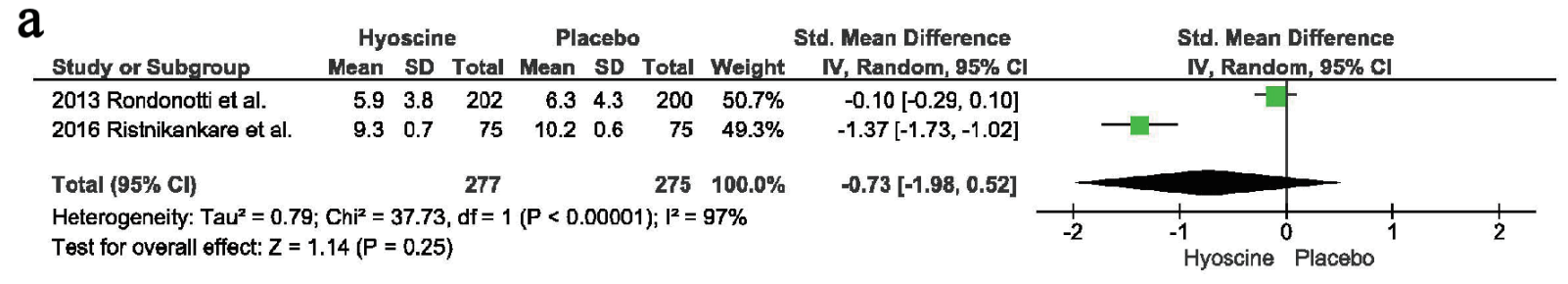

b

\begin{tabular}{|c|c|c|c|c|c|c|c|c|c|}
\hline Study or Subgroup & $\begin{array}{l}\text { Hyosci } \\
\text { Events }\end{array}$ & ine & $\begin{array}{l}\text { Placek } \\
\text { Events }\end{array}$ & $\begin{array}{l}\text { bo } \\
\text { Total }\end{array}$ & Weight & $\begin{array}{c}\text { Odds Ratio } \\
\text { M.H, Random, } 95 \% \mathrm{Cl}\end{array}$ & & $\begin{array}{c}\text { Odds Ratio } \\
\mathrm{M}-\mathrm{H}, \text { Random, } 95 \% \mathrm{Cl}\end{array}$ & \\
\hline 2013 Rondonotti et al. & 136 & 220 & 152 & 220 & $52.0 \%$ & $0.72[0.49,1.07]$ & & L & \\
\hline 2017 Santos et al. & 62 & 202 & 57 & 200 & $48.0 \%$ & $1.11[0.72,1.71]$ & & 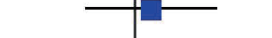 & \\
\hline Total $(95 \% \mathrm{Cl})$ & & 422 & & 420 & $100.0 \%$ & $0.89[0.59,1.35]$ & & & \\
\hline Total events & 198 & & 209 & & & & & & \\
\hline $\begin{array}{l}\text { Heterogeneity: } \mathrm{Tau}^{2}= \\
\text { Test for overall effect: } 2\end{array}$ & $\begin{array}{l}\text { 15; } \mathrm{Chi}^{2}= \\
=0.55(\mathrm{P}\end{array}$ & $\begin{array}{l}2.07, d \\
=0.58)\end{array}$ & $\mathrm{df}=1(\mathrm{P}=$ & $=0.15)$ & $\left.\right|^{2}=52 \%$ & & +1.2 & 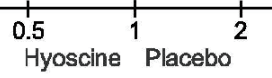 & 5 \\
\hline
\end{tabular}

c

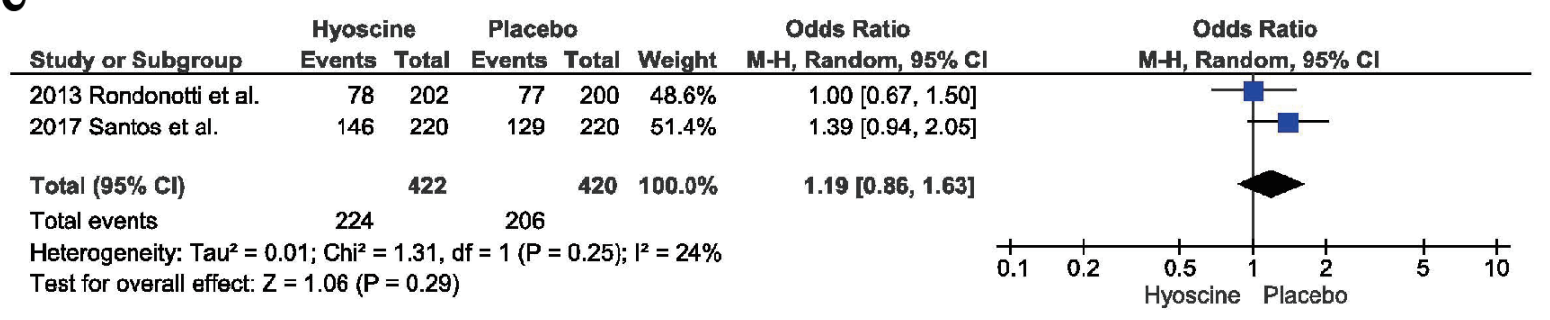

d

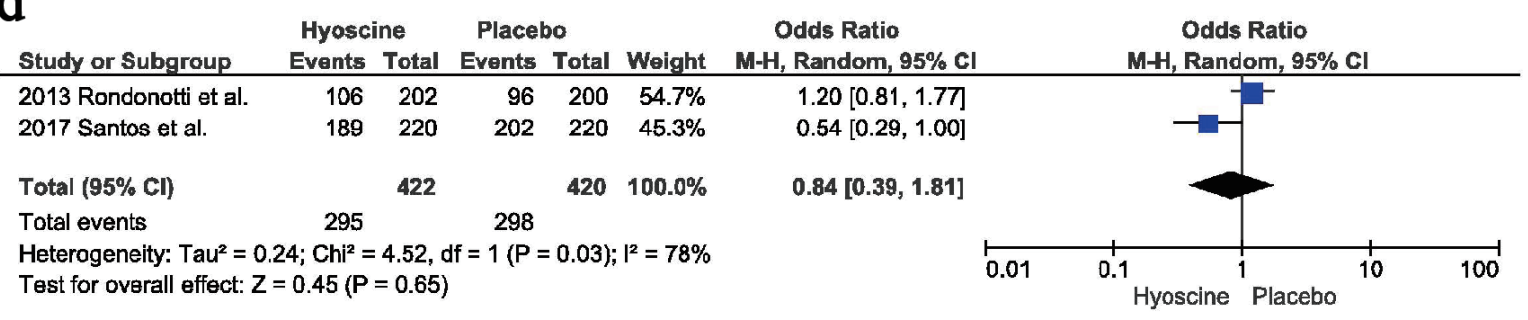

Figure 4. Secondary outcomes: (a) Cecal intubation time. (b) Polyp location proximal to splenic flexure. (c) Polyp location distal to splenic flexure. (d) Adenomatous polyps.

fore sensitivity analysis couldn't be performed (Fig. 4d).

\section{Discussion}

Data from several studies showed that colonoscopy could miss up to $22 \%$ of adenomas irrespective of their size [3]. Careful mucosal exploration of gut is a key factor in detection of polyps [4], and multiple strategies have been developed to improve the PDR such as use of chromoendoscopy [15], water immersion technique $[16,17]$ and Third Eye Retroscope [18]. Most colonoscopists use the withdrawal time to examine the colon for detecting polyps during colonoscopy. Strategies that involve visualizing mucosa around the flexures, proximal sides of folds and ileocecal valves have shown to yield higher polyp detection rates $[15,17]$.

Colonoscopy can be a challenge for the operator due to differences in anatomic mobility and folded structure of the intestinal mucosa [19]. Air insufflation used during the procedure can lead to intestinal wall or colonic mesentery distension causing discomfort for the patients. Moreover, mobile portions of the colon can lead to loop formation of colonoscope causing further unease to the patients $[20,21]$.

The benefit of colonoscopy in reducing incidence and mortality of CRC is more significant for distal than for proximal CRC [22, 23]. Non-polypoid lesions are more common on the right side of the colon and failure of colonoscopy to diagnose such lesions could partially explain the development of interval more aggressive neoplasms [24]. Failure to diagnose these lesions could be attributed to inadequate bowel preparation $[25,26]$, colonoscopy technique, colonoscope withdrawal time [27], and polyp location [28, 29].

Since the advent of colonoscopy, antispasmodics have been tried adjunctively in the certainty that the resultant reduction in colonic spasm would improve outcomes. Antispasmodic agents have a long history of use in colonoscopy for 
a variety of indications. Commonly used antispasmodics in colonoscopy were HBB, glucagon and peppermint oil. HBB is the well-studied anti-spasmolytic due to its low cost and acceptable safety profile. Radiologists commonly use HBB also for CT colonography and barium enema to facilitate mucosal exploration and decrease colonic motility [30, 31].

There has been controversial data regarding the use of anti-spasmolytic agents during colonoscopy to help improve PDR. Studies that have used atropine and glucagon as antispasmodic agents did not show benefit regarding intubation and total procedure time during colonoscopic procedures [32-34]. Initial data demonstrating the efficacy of antispasmodic came from two studies that showed the intravenous use of HBB led to significant decrease in total intubation time and degree of patient discomfort by reducing colon spasms [35, 36]. Two other large observational and retrospective studies reported improved polyp and adenoma detection in patients receiving $\mathrm{HBB}$ at the time of cecal intubation compared to placebo [37, 38]. HBB has been shown to facilitate ileal intubation in studies done by Ansari et al and Misra et al $[39,40]$. Some studies have shown HBB use before the procedure can lead to adverse effect on colonoscopy procedure time and patient discomfort. The postulated reason is that the decrease colonic muscle tone can make it difficult for the operator to reach the cecum $[6,41]$.

To explain the disparity in the results seen in the previous studies following aspects should be taken into consideration. These include smaller patient population studied, use of sedative medications, the dose and routes of anti-spasmolytic agents used and timing of administration of anti-spasmolytic agents. Even though antispasmodic drugs are cheap and safe, their anticholinergic properties have raised cardiovascular safety concerns [35].

We included seven RCTs with 2,588 patients in our analysis. A total of 1,301 patients were randomized to HBB arm and 1,287 to the placebo arm. The primary outcome variable was polyp detection rate. All the included studies for our meta-analysis were well-suited and homogeneous regarding design, reported outcomes, modality, dosage and timing of drug administration, and methods for blinding or masking. By pooled data, we found no differences between the two groups regarding the polyp detection rates, adenoma detection rates, and advanced lesion detection rates. We found no significant difference regarding polyp location proximal or distal to the splenic flexure and mean number of polyps detected. Among the two studies that reported the cecal intubation time, there was no difference between the two arms. Results from our meta-analysis question the use and efficacy of hyosamine during the colonoscopic procedures to improve PDR, ADR or AADR. On the contrary Madhoun et al in their meta-analysis pointed out marginal benefit regarding PDR and ADR in patients who received $\mathrm{HBB}$ during colonoscopy [41].

However, HBB seems to increase ADR and PDR in a subset of the population reported in earlier studies. Corte et al demonstrated higher polyp rate in HBB group when administered after cecal intubation as compared to placebo group [6]. Santos et al in their recently published RCT found a higher rate of non-polypoid lesions in the HBB group as compared to placebo group [7]. Lee at al showed that in a selected subgroup of patients with intense colonic spasms using non validated spasm score $>3$ HBB group had more significant ADR compared to placebo group [8]. However, all these RCTs revealed no statistical difference regarding ADR, PDR or advanced ADR in the hysoamine group compared to placebo.

Our paper has several limitations. One of the RCT did not use sedation during the procedure. They also gave HBB before the procedure and at time of cecal intubation [9]. Rest of the RCTs included in the analysis had patients on sedation during the colonoscopy, and HBB was given at the time of cecal intubation. Both these factors could have influenced the PDR or ADR by altering the degree of colonic spasms. The second limitation was that only two RCTs reported cecal intubation time $[9,10]$ and polyp location $[7,10]$ which makes it difficult to generalize the results of these two outcomes. The third limitation was that Ristikankare et al reported their mean number of polyps without standard deviation [9]. Therefore we could not use their outcomes in our analysis. Another limitation of the study includes that pathology was not reviewed.

\section{Conclusions}

Our meta-analysis showed HBB used during a colonoscopy does not improve PDR or ADR. It showed a non-significant trend of increased mean number of polyps detected with HBB. However few studies have shown the potential benefit of HBB when administered to a subgroup of the population such as with marked colonic spasms. Further RCTs are required focusing on this population to determine any real benefit of $\mathrm{HBB}$ in improving ADR or PDR.

\section{Conflict of Interest}

There was no conflict of interest to report.

\section{Funding Support}

We did not receive any funding for any aspect of this study.

\section{References}

1. Rex DK, Bond JH, Winawer S, Levin TR, Burt RW, Johnson DA, Kirk LM, et al. Quality in the technical performance of colonoscopy and the continuous quality improvement process for colonoscopy: recommendations of the U.S. Multi-Society Task Force on Colorectal Cancer. Am J Gastroenterol. 2002;97(6):1296-1308.

2. Wallace MB. Improving colorectal adenoma detection: technology or technique? Gastroenterology. 2007;132(4):1221-1223.

3. van Rijn JC, Reitsma JB, Stoker J, Bossuyt PM, van Deventer SJ, Dekker E. Polyp miss rate determined by tandem colonoscopy: a systematic review. Am J Gastro- 
enterol. 2006;101(2):343-350.

4. East JE, Saunders BP, Burling D, Boone D, Halligan S, Taylor SA. Surface visualization at CT colonography simulated colonoscopy: effect of varying field of view and retrograde view. Am J Gastroenterol. 2007;102(11):25292535.

5. Liberati A, Altman DG, Tetzlaff J, Mulrow C, Gotzsche PC, Ioannidis JP, Clarke M, et al. The PRISMA statement for reporting systematic reviews and meta-analyses of studies that evaluate healthcare interventions: explanation and elaboration. BMJ. 2009;339:b2700.

6. Corte C, Dahlenburg L, Selby W, Griffin S, Byrne C, Chua T, Kaffes A. Hyoscine butylbromide administered at the cecum increases polyp detection: a randomized double-blind placebo-controlled trial. Endoscopy. 2012;44(10):917-922.

7. Dos Santos CEO, Moreira H, Pereira-Lima JC, Ribas C, de Quadros Onofrio F, Czecko AEA, Ramos RK, et al. Hyoscine butylbromide for colorectal polyp detection: prospective, randomized, placebo-controlled trial. Clinics (Sao Paulo). 2017;72(7):395-399.

8. Lee JM, Cheon JH, Park JJ, Moon CM, Kim ES, Kim TI, Kim WH. Effects of Hyosine N-butyl bromide on the detection of polyps during colonoscopy. Hepatogastroenterology. 2010;57(97):90-94.

9. Ristikankare M, Karinen-Mantila $\mathrm{H}$. The role of routinely given hyoscine-N-butylbromide in colonoscopy: a double-blind, randomized, placebo-controlled, clinical trial. Scand J Gastroenterol. 2016;51(3):368-373.

10. Rondonotti E, Radaelli F, Paggi S, Amato A, Imperiali G, Terruzzi V, Mandelli G, et al. Hyoscine N-butylbromide for adenoma detection during colonoscopy: a randomized, double-blind, placebo-controlled study. Dig Liver Dis. 2013;45(8):663-668.

11. de Brouwer EJ, Arbouw ME, van der Zwet WC, van Herwaarden MA, Ledeboer M, Jansman FG, ter Borg F. Hyoscine N-butylbromide does not improve polyp detection during colonoscopy: a double-blind, randomized, placebo-controlled, clinical trial. Gastrointest Endosc. 2012;75(4):835-840.

12. Byun TJ, Han DS, Ahn SB, et al. Role of intravenous hyoscine N-butyl bromide at the time of colonoscopic withdrawal for polyp detection rates: A randomized, double-blinded, placebo-controlled trial. Gastrointestinal Endoscopy. 2009;69(5):AB229.

13. Higgins JP, Altman DG, Gotzsche PC, Juni P, Moher D, Oxman AD, Savovic J, et al. The Cochrane Collaboration's tool for assessing risk of bias in randomised trials. BMJ. 2011;343:d5928.

14. Higgins JPT GD. Cochrane Handbook of Systematic Reviews of Interventions 5.1.0 Part 2: General Methods for Cochrane Reviews. The Cochrane Collaboration 2011. Available at: http://handbook.cochrane.org/chapter_9/9_5_2_identifying_and_measuring heterogeneity. htm.

15. Brown SR, Baraza W, Hurlstone P. Chromoscopy versus conventional endoscopy for the detection of polyps in the colon and rectum. Cochrane Database Syst Rev. 2007;4:CD006439.
16. Leung FW. Water exchange may be superior to water immersion for colonoscopy. Clin Gastroenterol Hepatol. 2011;9(12):1012-1014.

17. Leung F, Harker J, Leung J, Siao-Salera R, Mann S, Ramirez F, Friedland S, et al. Removal of infused water predominantly during insertion (water exchange) is consistently associated with an increase in adenoma detection rate - review of data in randomized controlled trials (RCTs) of water-related methods. J Interv Gastroenterol. 2011;1(3):121-126.

18. Leufkens AM, DeMarco DC, Rastogi A, Akerman PA, Azzouzi K, Rothstein RI, Vleggaar FP, et al. Effect of a retrograde-viewing device on adenoma detection rate during colonoscopy: the TERRACE study. Gastrointest Endosc. 2011;73(3):480-489.

19. Brown SR, Baraza W. Intravenous hyoscine-N-butyl bromide for aiding colonoscopy. The Cochrane Library. 2013.

20. Hull T, Church JM. Colonoscopy - how difficult, how painful? Surg Endosc. 1994;8(7):784-787.

21. Cotton PB, Williams CB, Hawes RH, Saunders BP. Practical gastrointestinal endoscopy: the fundamentals. Wiley Online Library; 2003.

22. Baxter NN, Goldwasser MA, Paszat LF, Saskin R, Urbach DR, Rabeneck L. Association of colonoscopy and death from colorectal cancer. Ann Intern Med. 2009;150(1):1-8.

23. Singh H, Nugent Z, Demers AA, Kliewer EV, Mahmud $\mathrm{SM}$, Bernstein $\mathrm{CN}$. The reduction in colorectal cancer mortality after colonoscopy varies by site of the cancer. Gastroenterology. 2010;139(4):1128-1137.

24. dos Santos CE, Malaman D, Monkemuller K, Dos Santos Carvalho T, Lopes CV, Pereira-Lima JC. Prevalence of non-polypoid colorectal neoplasms in southern Brazil. Dig Endosc. 2015;27(3):361-367.

25. Marmo R, Rotondano G, Riccio G, Marone A, Bianco MA, Stroppa I, Caruso A, et al. Effective bowel cleansing before colonoscopy: a randomized study of split-dosage versus non-split dosage regimens of high-volume versus low-volume polyethylene glycol solutions. Gastrointest Endosc. 2010;72(2):313-320.

26. Menacho AM, Reimann A, Hirata LM, Ganzerella C, Ivano FH, Sugisawa R. Double-blind prospective randomized study comparing polyethylene glycol to lactulose for bowel preparation in colonoscopy. Arq Bras Cir Dig. 2014;27(1):9-12.

27. Barclay RL, Vicari JJ, Doughty AS, Johanson JF, Greenlaw RL. Colonoscopic withdrawal times and adenoma detection during screening colonoscopy. N Engl J Med. 2006;355(24):2533-2541.

28. Pickhardt PJ, Nugent PA, Mysliwiec PA, Choi JR, Schindler WR. Location of adenomas missed by optical colonoscopy. Ann Intern Med. 2004;141(5):352-359.

29. Silva SM, Rosa VF, Santos AC, Almeida RM, Oliveira PG, Sousa JB. Influence of patient age and colorectal polyp size on histopathology findings. Arq Bras Cir Dig. 2014;27(2):109-113.

30. Tytgat GN. Hyoscine butylbromide - a review on its parenteral use in acute abdominal spasm and as an aid in abdominal diagnostic and therapeutic procedures. Curr Med 
Res Opin. 2008;24(11):3159-3173.

31. Dyde R, Chapman AH, Gale R, Mackintosh A, Tolan DJ. Precautions to be taken by radiologists and radiographers when prescribing hyoscine-N-butylbromide. Clin Radiol. 2008;63(7):739-743.

32. Cutler CS, Rex DK, Hawes RH, Lehman GA. Does routine intravenous glucagon administration facilitate colonoscopy? A randomized trial. Gastrointest Endosc. 1995;42(4):346-350.

33. Waxman I, Mathews J, Gallagher J, Kidwell J, Collen MJ, Lewis JH, Cattau EL, Jr., et al. Limited benefit of atropine as premedication for colonoscopy. Gastrointest Endosc. 1991;37(3):329-331.

34. Norfleet RG. Premedication for colonoscopy: randomized, double-blind study of glucagon versus placebo. Gastrointest Endosc. 1978;24(4):164-165.

35. Marshall JB, Patel M, Mahajan RJ, Early DS, King PD, Banerjee B. Benefit of intravenous antispasmodic (hyoscyamine sulfate) as premedication for colonoscopy. Gastrointest Endosc. 1999;49(6):720-726.

36. Saunders BP, Williams CB. Premedication with intrave- nous antispasmodic speeds colonoscope insertion. Gastrointest Endosc. 1996;43(3):209-211.

37. Lee TJ, Rees CJ, Blanks RG, Moss SM, Nickerson C, Wright KC, James PW, et al. Colonoscopic factors associated with adenoma detection in a national colorectal cancer screening program. Endoscopy. 2014;46(3):203-211.

38. Khan JG. Use of buscopan improves polyp detection rate during colonoscopy withdrawal (a retrospective audit). Europ Surg-Acta Chir Austriaca. 2011;43:S240.

39. Ansari A, Soon SY, Saunders BP, Sanderson JD. A prospective study of the technical feasibility of ileoscopy at colonoscopy. Scand J Gastroenterol. 2003;38(11):11841186.

40. Misra SP, Dwivedi M. Role of intravenously administered hyoscine butyl bromide in retrograde terminal ileoscopy: a randomized, double-blinded, placebo-controlled trial. World J Gastroenterol. 2007;13(12):1820-1823.

41. Madhoun MF, Ali T, Tierney WM, Maple JT. Effect of hyoscine N-butylbromide on adenoma detection rate: meta-analysis of randomized clinical trials. Dig Endosc. 2015;27(3):354-360. 